\title{
Pycnogonida collected in interstitia of coral sand and rubble in the Netherlands Antilles
}

\author{
Amsterdam Expeditions to the West Indian Islands, Report 58*
}

Jan H. Stock

Institute of Taxonomic Zoology, University of Amsterdam, P.O. Box 4766, 1009 AT Amsterdam, The Netherlands

Keywords: Pycnogonida, interstitial, Curaçao, Bonaire

\begin{abstract}
Seven species of Pycnogonida are recorded from the islands of Curaçao and Bonaire, living in coral debris (sand, rubble), often quite deep (40-80 cm) in the sediment. Two species (both new) occur in larger numbers and are considered truly interstitial. The others possibly are only accidental in this kind of habitat.
\end{abstract}

\section{Résumé}

Sept espèces de Pycnogonides sont signalées dans un habitat spécial des îles de Curaçao et de Bonaire: les débris de coraux (sable, gravier), les animaux étant souvant très profondement enfouis dans les sédiments $(40-80 \mathrm{~cm})$. Deux espèces (l'une et l'autre nouvelles) sont rencontrées en nombres importants d'exemplaires et sont considérées comme de vraies formes interstitielles. La présence des autres est probablement seulement accidentelle dans ce type d'habitat.

\section{Introduction}

Interstitial Pycnogonida are rare and belong essentially to five genera only (Stock, 1986). The present paper describes the Pycnogonida collected in coarse coral sand and rubble of the islands of Curaçao and Bonaire in the Netherlands Antilles. The samples were taken either by washing sand in a bucket and then filtering the supernatant over a $300 \mu \mathrm{m}$ filter, or by means of a biophreatical pump (description of this apparatus in Bou, 1975). The probe of this pump can be hammered into the sediment, and per- mits pumping up the infauna at discrete depths under the sediment surface varying from 30 to over $200 \mathrm{~cm}$. Pycnogonida were encountered mainly from 40 to $80 \mathrm{~cm}$ under the surface.

Two species were relatively common in our samples, one belonging to the genus Rhynchothorax Costa, 1861, the other to the genus Hedgpethius Child, 1974. These two genera were already signalized from interstitial habitats (Stock, 1986).

Of the remaining species, only one or a very few specimens were encountered, suggesting that they are no real stygobionts, but only accidentally introduced into the samples from surface waters.

All specimens mentioned in this report are preserved in the Zoölogisch Museum Amsterdam (ZMA).

\section{Family AMMOTHEIDAE}

\section{Achelia sawayai Marcus, 1940}

Material. - 1 juv.; BONAIRE, Stn. 84-226, shore of Lac near Sorobon $\left(12^{\circ} 05^{\prime} 53^{\prime \prime} \mathrm{N} 68^{\circ} 14^{\prime} 02^{\prime \prime} \mathrm{W}\right)$, washed from medium-coarse coral sand on high water mark, 11 June 1984.

- 1 o ovig., 1 juv.; CURAÇAO, Stn. 84-49, Playa Forti $\left(12^{\circ} 22^{\prime} 12^{\prime \prime} \mathrm{N} 69^{\circ} 09^{\prime} 07^{\prime \prime} \mathrm{W}\right)$, washed from infralittoral clean sand and gravel, water depth 150-200 cm, 14 may 1984 .

Remarks. - This is a common amphi-atlantic,

\footnotetext{
* Report 57 has been published in Bijdr. Dierk., 59(1) (1989).
} 


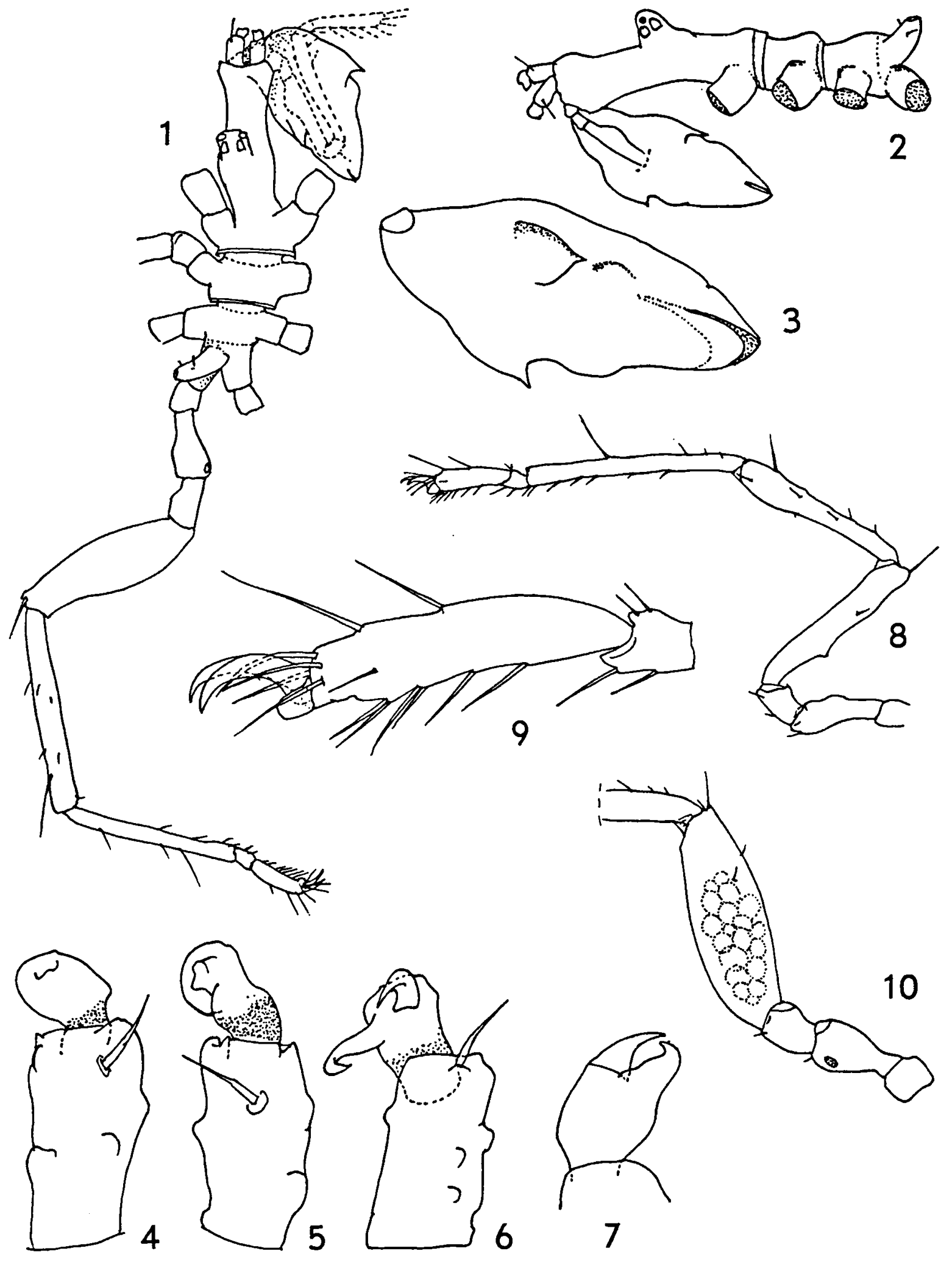


tropical species, frequently recorded from noninterstitial habitats.

\section{Hedgpethius interstitialis n.sp.}

Material (all from CURAÇAO):

- $10^{\circ}$ (holotype), 1 \% (allotype), $20^{\circ} 0^{\circ}$ and 8

१ ९ (paratypes); Stn. 84-37, Boca Tabia, E.-side $\left(12^{\circ} 22^{\prime} 19^{\prime \prime} \mathrm{N} 69^{\circ} 06^{\prime} 49^{\prime \prime} \mathrm{W}\right)$; strongly exposed intertidal rockpool, washed from coarse sand; 11 May 1984 (ZMA Pa. 3304).

- 1 o juv.; Stn. 84-36, Boca Tabla (as previous station), in coarse sand on loamy layer of strongly exposed beach near high water mark; 11 May 1984. - 1 o"; Stn. 84-114, Kennedy Boulevard, ca. 500 $m$ E. of Concorde Hotel $\left(12^{\circ} 07^{\prime} 13^{\prime \prime} \mathrm{N}\right.$ $68^{\circ} 57^{\prime} 50^{\prime \prime} \mathrm{W}$ ); sand and coral rubble, $\mathrm{H}_{2} \mathrm{~S}$-rich; shore of small lagoon, $6 \mathrm{~m}$ inland from high tide mark; salinity 42 p.p.t.; 27 May 1984.

- 8 ó O', 4 ९ \% Stn. 84-136, same locality as $84-114$, but 2 to $4 \mathrm{~m}$ inland of high tide mark; BouRouch pump, ca. $80 \mathrm{~cm}$ under substrate surface; chlorinity $29526 \mathrm{mg} / \mathrm{l} ; 31$ May 1984.

- 7 ơ o , 3 \% \& ; Stn. 84-139, same locality as $84-136$, but $75 \mathrm{~cm}$ under substrate surface; 1 June 1984.

- 1 \%; Stn. 84-149, Westpunt, Rooi Boca Cortalijn (12 $\left.22^{\prime} 31^{\prime \prime} \mathrm{N} 69^{\circ} 07^{\prime} 30^{\prime \prime} \mathrm{W}\right)$; well with salty water near coast; 2 June 1984.

Description. - General shape of body and proboscis (figs. 1-3) very similar to that of $\boldsymbol{H}$. mamillatus Child, 1982.

Chelifore (figs. 4-5) scape 1-segmented, ornamented with several naked tubercles and 1 very strong dorsolateral seta; distal end of scape excavated. Basal part of chela membranaceous, retractable in distal scape excavation; distal part of chela globular. Fingers usually reduced to knobs or chitinous folds; in juvenile (fig. 7) fingers still present, curved, gaping, unarmed. Sometimes, long, curved fingers persist in adults (fig. 6).

Palp 7-segmented (figs. 11-12); segment 3 with large ventral swelling in basal part; segment 5 very thin and slender, longer than segment 3; segment 7 very slender, slightly more than half as long as segment 5,7 to 8 times as long as wide.

Oviger of $\$$ (fig. 15) 3-segmented, unarmed; distal segment globular. Oviger of $\sigma^{\circ}$ (figs. 13-14) 9or 10-segmented (distal segment may be subdivided or not). Segment 2 longest; segment $3<$ segment 4; segment $4 \geq$ segment 5 ; segment 6 with large distal lobe; segment 7 articulated anaxially with segment 6; segments 7 and 8 unarmed. Distal segment(s) with 3 unadorned spines; segmentation line dividing this segment usually vestigial, sometimes welldeveloped.

Legs (fig. 8) resembling those of $H$. mamillatus. Coxa 2 of $\sigma^{\circ}$ more slender than that of $\$$. Femur of $\$$ swollen, containing ovaria (fig. 10). Femur of o with dorsal cement gland, placed at one-third of femoral length, opening through raised pore. Gland aperture never duct-like, though slightly variable in shape (figs. 16-18): in the type-locality (a very exposed beach), it is crater-shaped, in less exposed localities it is a low chimney or an asymmetrical cone. Shape of aperture can vary on different legs of same specimen. Auxiliary claws long, strongly curved; main claw rudimentary, present as a rounded vestige (fig. 9).

Measurements of $\$$ (paratype) in $\mu \mathrm{m}$. - Length trunk (frontal margin cephalic segment to tip 4th lateral process) 586; length cephalic segment 345 ; width across 2nd lateral processes 197.

Third leg: first coxa 72; second coxa 160; third coxa 93; femur 366; first tibia 367; second tibia 409; tarsus 19; propodus 136; auxiliary claws 66 .

Remarks. - Hedgpethius contained hitherto two species: $H$. tridentatus Child, 1974 (additional data in Child, 1982), and H. mamillatus Child, 1982. Both species are Caribbean. The new species differs markedly from $H$. tridentatus by the position of the ocular tubercle (in the central part of neck, instead

Figs. 1-10. Hedgpethius interstitialis n. sp. (from Stn. 84-37, unless otherwise stated): 1, ९, dorsal (scale a); 2, ९, from the left (a); 3 , proboscis, $Q$, from the right (b); 4, 5, chelifore, $\sigma$ (c); 6, chelifore, $\sigma$, with neotenic chela, from Stn. 84-136 (c); 7, chela of juvenile, from Stn. 84-36 (c); 8, third leg, $\sigma^{\circ}$ (a); 9, propodus of third leg, $\sigma$ (d); 10, proximal segments of third leg, $\$$ (a). 

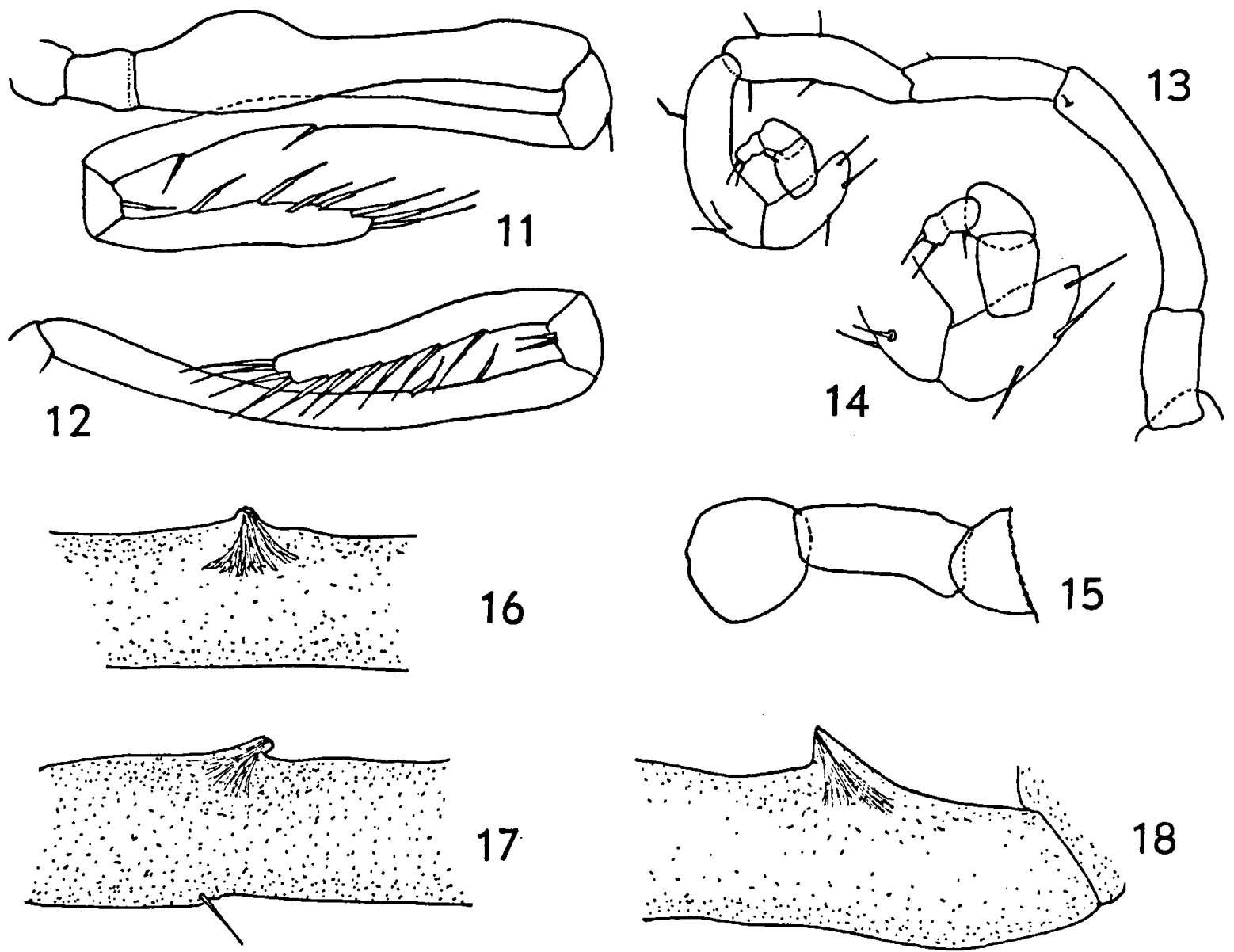

Figs. 11-18. Hedgpethius interstitialis n. sp. (from Stn. 84-37, unless otherwise stated): 11, palp, ơ (scale d); 12, distal palp segments, $\$$ (d); 13, oviger, $\sigma^{\circ}(\mathrm{e}) ; 14$, distal oviger segments, $\sigma^{\circ}$ (d); 15, oviger, $\odot$ (c); 16, cement gland on third leg, $\sigma^{\circ}$ (d); 17 , cement gland on second leg, $\sigma$, from Stn. 84-136 (d); 18, cement gland on fourth leg, $\sigma$, from Stn. 84-139 (d).

of in the anterior part), the number of palp segments (7 instead of 8 ), the cement gland (opening through a low cone, not through a long duct), and the vestigial condition of the main claw of the legs.

In all these characters, the new species agrees with $H$. mamillatus. Unfortunately, only the female sex of that species is known. Our comparison thus has to remain restricted to this sex. The most striking difference resides in the distal palp segment, which is 4 times as long as wide (and about one-third of the length of segment 5) in mamillatus, whereas it is 7 to 8 times as long as wide (and slightly over half the length of segment 5) in the new species.

Child (1982) interprets the chelifore scape as 2-segmented; in my specimens, the presumed second segment looks more like a flexible connecting membrane between the chela and the excavated distal end of the scape.

Perhaps the main claw of the legs is slightly less reduced in the new species than it is in $H$. mamillatus.

This is the most common interstitial pycnogonid in Curaçao. Because of its small size, it is easily collected using a biophreatical pump. It has been found as deep as 75 to $80 \mathrm{~cm}$ below the substrate top, sometimes in waters with a very low oxygen content (saturation $<10 \%$ ), together with several other stygobionts, like Halosbaena (Thermosbaenacea), Saliweckelia (Amphipoda), Salmoneus 


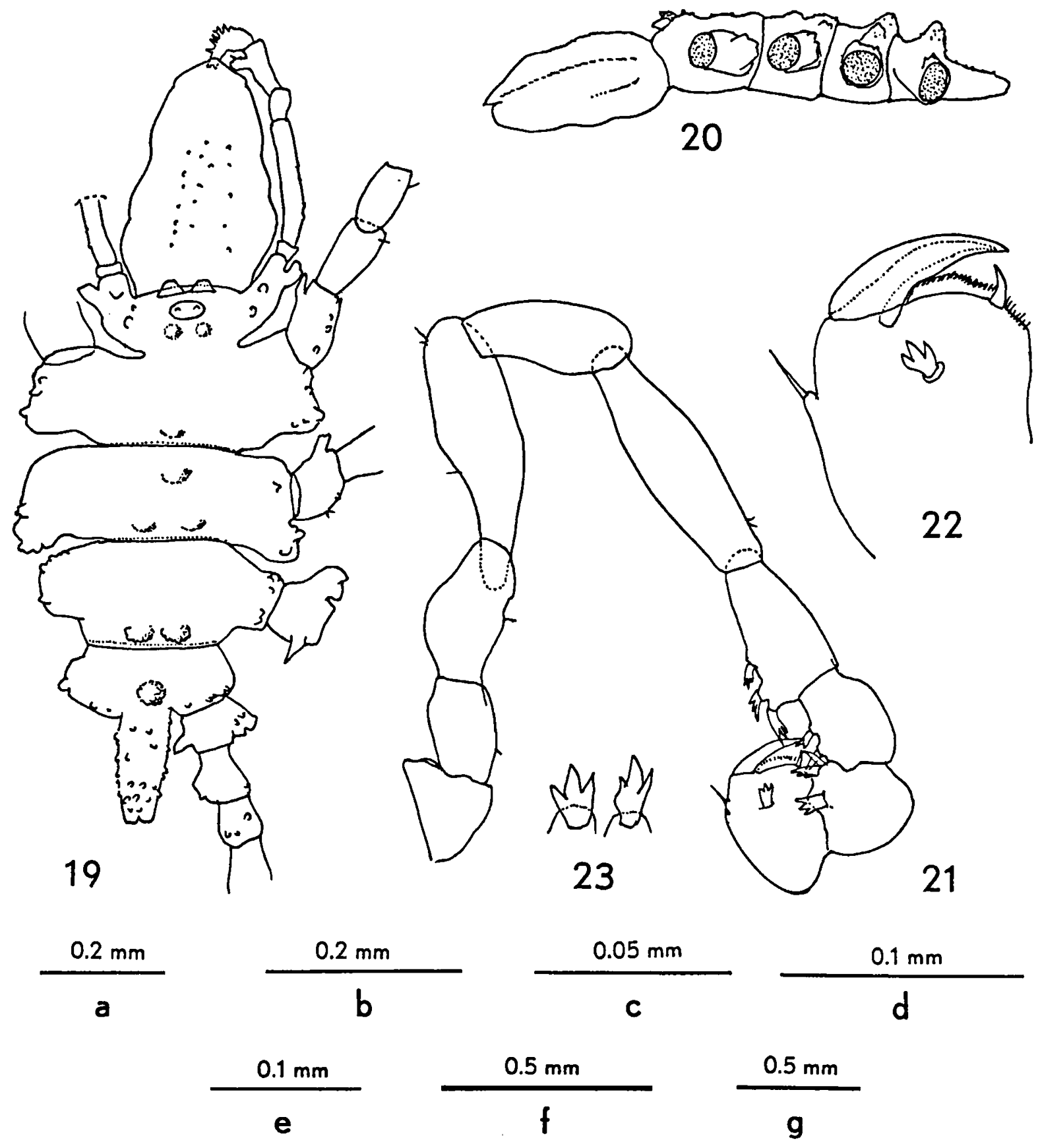

Figs. 19-23. Rhynchothorax arenicolus $n$. sp. (from Stn. 84-37). 19, $\sigma^{\circ}$, dorsal (scale f); 20, $\sigma$, from the left (g); 21, oviger, $\sigma^{\circ}$ (b); 22 , tip of oviger, $\sigma^{\circ}(\mathrm{c}) ; 23$, compound spines of oviger segment 9 , $\sigma^{\circ}$ (free-hand sketch).

(Decapoda), Caecum (Gastropoda), and Curassanthura (Isopoda). The specific name, interstitialis, refers to this infaunal habitat.

Figs. 32 and 33 show the habitat of Hedgpethius: in Boca Tabla (fig. 32) it lives on a very exposed beach, where the trade winds produce waves of several metres high; on the Kennedy Boulevard, which is located on the leeward side of the island, exposition is much less (fig. 33). 


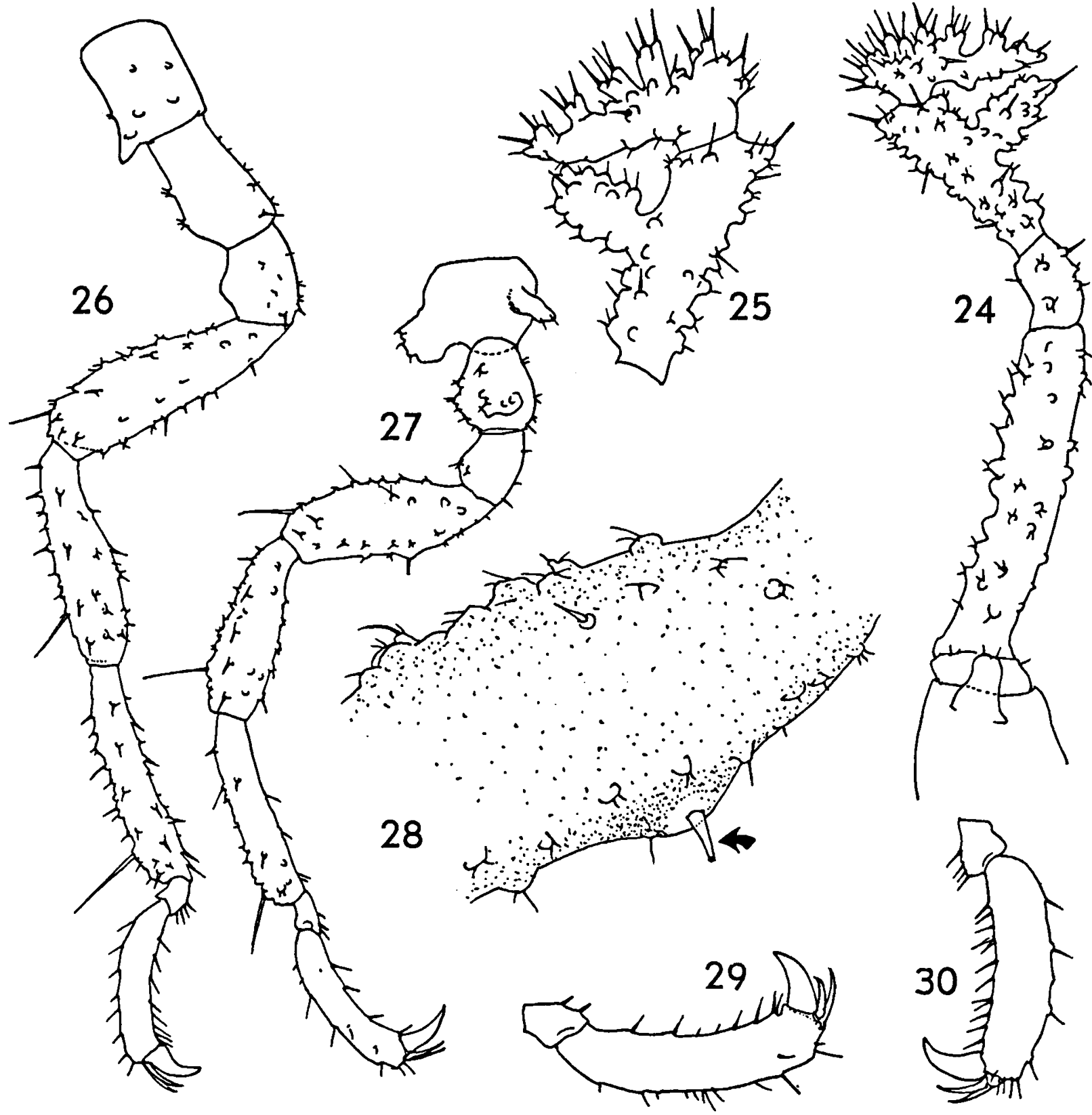

Figs. 24-30. Rhynchothorax arenicolus n. sp. (from Stn. 84-37, unless otherwise stated). 24, palp, $\sigma$ (scale b); 25, distal palp segments, Q ?, from Stn. 84-29 (e); 26, first leg, $\sigma^{\circ}$ (a); 27, third leg, $\sigma$ (a); 28, cement gland (arrow) of third leg, $\sigma^{\circ}$ (d); 29, distal segments of fourth leg, $९$ ?, from Stn. 84-29 (b); 30, ditto of second leg, ९ ?, from Stn. 84-29 (d).

\section{Rhynchothorax arenicolus n. sp.}

Material (all from CURAÇAO):

- $10^{\circ}$ (holotype), $10^{\circ}$ (paratype); Stn. 84-37, E. side of Boca Tabla $\left(12^{\circ} 22^{\prime} 19^{\prime \prime} \mathrm{N} 69^{\circ} 06^{\prime} 49^{\prime \prime} \mathrm{W}\right)$, washed from coarse sand of rockpool, water depth
11-20 $\mathrm{cm}$, very exposed to trade wind driven waters; 11 may 1984 (ZMA Pa. 3305).

- 1 specimen (young $\&$ ?); Stn. 84-29, same place as 84-37, but pumped up with biophreatical pump; depth under substrate surface $50 \mathrm{~cm}$; 9 May 1984 . 


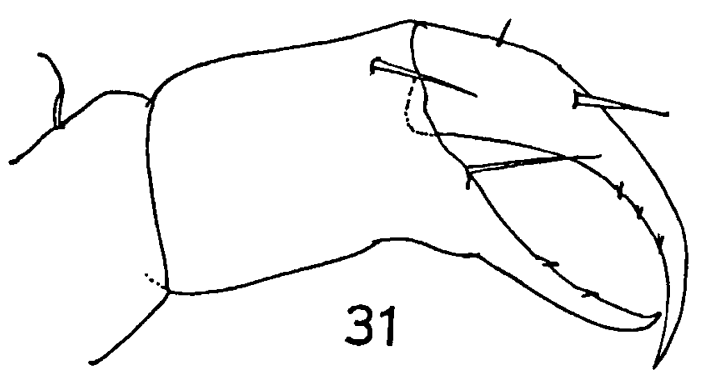

Fig. 31. Anoplodactylus allotrius Child, 1979, ${ }^{\circ}$, from Stn. 84-63: chela (scale d).

- 1 O $^{\prime \prime}$ (paratype); Stn. 84-145, same place and method as $84-29,55 \mathrm{~cm}$ under substrate surface; 2 June 1984 (ZMA Pa. 3306).

Description. - Male: Trunk (figs. 19-20) completely segmented. Palps arising from strong anterior extension of cephalic segment; this extension bearing conspicuous lateral tubercle. Ocular tubercle reduced to a small, low, rounded boss; no eyes. Two low bosses arise behind ocular tubercle. In front of ocular tubercle, 2 touching processes are interpreted as rudiments of chelifores (because they have an articulation line at their base). First lateral process without anterior boss; with strong, slightly tuberculated, but unbranched posterior lobe. Trunk segment 1 with obsolete mid-dorsal tubercle at posterior margin; trunk segment 2 with 1 anterior and 2 posterior, low bosses; trunk segment 3 with 2 distinct posterior bosses; trunk segment 4 with 1 distinct mid-dorsal boss. Second lateral process with markedly tuberculated posterior boss, third and fourth slightly tuberculated, without boss. Abdomen reaching to end of coxa 2 of leg 4, slightly tuberculate.

Proboscis with dorsal antimere, with 2 lateroventral bosses; dorsal surface with inconspicuous tubercles only.

Palp (figs. 24-25) 5-segmented. Segment 1 inconspicuous, very narrow; segment 2 very slender; segment 3 short; segment 4 strongly tuberculate, with very strong dorsal process, opposing the anaxially articulated segment 5 ; segment 5 with 5 or 6 branched or bifid processes on frontal margin, strongly spiniferous; greatest dimension of segment 5 almost equal to length of segment 4.

Oviger (fig. 21) 10-segmented, conforming usual shape in Rhynchothorax. Trifid compound spines (fig. 23) on segments 7 to 10 , according to formula 3:2:3:1. Segment 9, and in particular segment 10 , swollen, the latter subchelate (fig. 22). Terminal claw unornamented, opposing broad hyaline, serrate membrane of segment 10; tip of claw opposing heavy, curved spine of segment 10 .

Coxa 1 of legs 1 (fig. 26) and 2 with 1 anterior process; coxa 1 of legs 3 (fig. 27) and 4 with 1 large anterior and 1 smaller posterior process. Femur and tibiae slender, tuberculate and spiniferous. Propodal sole of legs 1 and 2 (fig. 30) with 7 to 12 spines; that of legs 3 and 4 (fig. 29) with 4 to 6 spines. Claw short, robust, curved. Auxiliary claws about twothirds of main claw. Femur of leg 3 only (in all 3 males examined) with slight but distinct ventral swelling, on which the very small femoral gland tube arises (fig. 28).

Female: The smallest specimen in the collection has no cement gland ducts and may be a female (or a juvenile?). Oviger segments 4 and 6 of this specimen much less slender than in other specimens.

Measurements (in $\mu \mathrm{m}$ ) of $\sigma^{\prime}$ holotype: Length trunk (frontal margin cephalic segment to tip abdomen) 1414; length proboscis (dorsal) 634; greatest diameter proboscis 364 ; width across 2 nd lateral processes 649.

First leg (third leg in parentheses): first coxa 189 (152); second coxa 186 (154); third coxa 145 (128); femur 378 (284); first tibia 340 (273); second tibia 345 (289); tarsus 46 (49); propodus 238 (238); claw 68 (77).

Etymology. - The specific name, arenicolus, alludes to the psammophilous habitat of the species. The animals have been found as deep as $55 \mathrm{~cm}$ under the substrate surface.

Remarks. - The new species fits well in Krapp's (1973: 123) group D of the genus Rhynchothorax, characterized by the presence of only 1 small distal palp segment, the presence of a strong dorsal process on the penultimate palp segment (forming a kind of pseudochela with the terminal segment), the presence of auxiliary claws, the presence of a dorsal antimere in the proboscis, and the absence of 


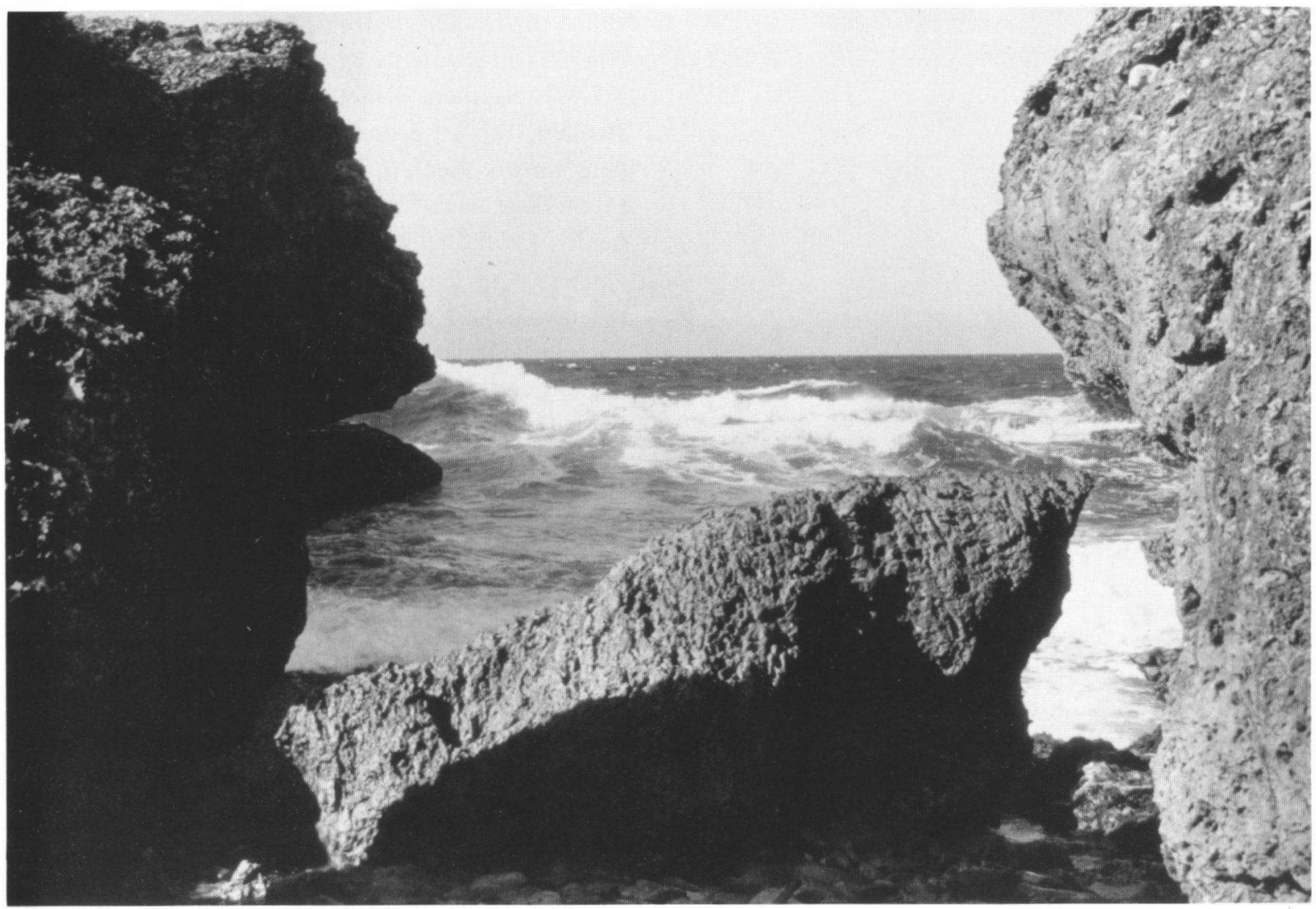

Fig. 32. Boca Tabla, Curaçao. The type-Iocality of Rhynchothorax arenicolus and Hedgpethius interstitialis is at the lower right of the photograph.

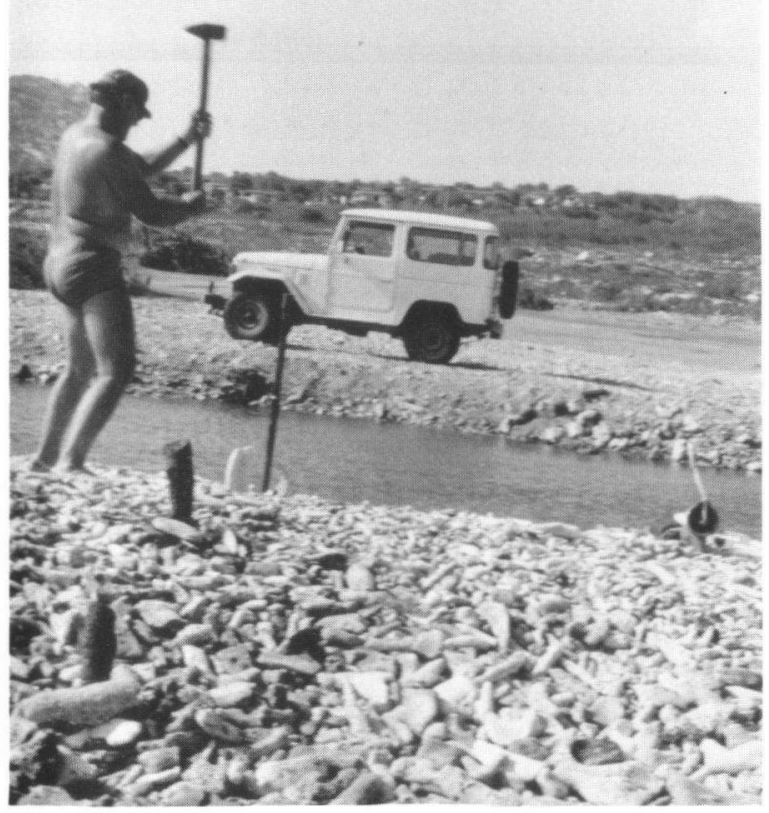

eyes. (It should be noted, however, that Clark, 1976, is hesitant in accepting Krapp's four species groups.)

To group D belong $R$. philopsammus Hedgpeth, $1951, R$. anophthalmus Arnaud, 1972, $R$. alcicornis Krapp, 1973, $R$. architectus Child, 1979, and an undescribed species from the Society Islands (Müller, in prep.).

In many respects the new species agrees with $R$. architectus, a variable species from the Pacific and Atlantic coasts of Panamá and from Belize (Child, $1979,1982)$, but it differs in the following respects: (1) distal palp segment almost as long as the penultimate segment (shorter in architectus); (2) distal

Fig. 33. Kennedy Boulevard, Curaçao. The pipe of a Bou-Rouch biophreatical pump is hammered into a bank of supralittoral coral rubble where Hedgpethius interstitialis is abundant. 
palp segment with branched processes (with simple tubercles in architectus); (3) dorsal tuberculation of proboscis inconspicuous (more important in architectus); (4) propodal spines somewhat more numerous; (5) femoral gland duct short, present only on leg 3 (longer and present on all legs in architectus).

The shape and ornamentation of the distal palp segment is characteristic of $R$. arenicolus: In $R$. philopsammus and $R$. anophthalmus, this segment is rounded and non-tuberculate; in $R$. architectus, $R$. spec. from the Society Islands, and $R$. alcicornis, it is shorter than the penultimate segment, although in the latter it bears branched processes (like antlers of an elk) just as in the new species. However, $R$. alcicornis has bacilliform chelifores (or cheliforelike processes) and the longest palp segment is less elongate than in $R$. arenicolus.

Fig. 32 shows the type-locality, the exposed beach of Boca Tabla.

\section{Family CALLIPALLENIDAE}

Pigrogromitus timsanus Calman, 1922

Material. - 3 specimens; Stn. 84-40, CURAÇAO, Piscadera Bay, in front of the Caribbean Marine Biological Institute; stones, sand, coral debris; water depth 60-75 cm; biophreatical pump $80 \mathrm{~cm}$ under substrate surface; 12 April 1984.

Remarks. - The occurrence of this common circumtropical species in a pump sample is probably accidental.

\section{Family PHOXICHILIDIIDAE}

Anoplodactylus allotrius Child, 1979

Child, 1979: 48-50, fig. 16.

Material. - 1 o ovig; Stn. 84-63, CURAÇAO, Piscadera Bay, first buoy $\left(12^{\circ} 07^{\prime} 45^{\prime \prime} \mathrm{N}\right.$ $68^{\circ} 58^{\prime} 27^{\prime \prime} \mathrm{W}$ ); water depth 3-4 m; airlift method in coarse coral sand; 18 May 1984.

Remarks. - This specimen clearly resembles the type series from Galeta Island (Panamá Caribbean). As far as I know, this is the second record of this species, and the fourth specimen to become known. The only difference with Child's figures of the holotype is found in the chela which has a few minute teeth on the movable and immovable finger (fig. 31).

Anoplodactylus batangensis (Helfer, 1938)

Material. - 1 \&, Stn. 84-49, CURAÇAO, Playa Forti $\left(12^{\circ} 22^{\prime} 12^{\prime \prime} \mathrm{N} 69^{\circ} 09^{\prime} 07^{\prime \prime} \mathrm{W}\right)$; in sublittoral sand and gravel, water depth $150-200 \mathrm{~cm} ; 14$ May 1984.

Remark. - A common circumtropical species, the occurrence of which in infralittoral sands no doubt is accidental.

\section{Anoplodactylus sp.}

Material. - 1 larva; Stn. 84-155, CURAÇAO, Piscadera Bay, in front of Caribbean Marine Biological Station, $4 \mathrm{~m}$ seaward of high tide mark, biophreatical pump in coral debris and fine sand, 40 cm under sediment surface; 3 June 1988.

Remark. - This may be a true interstitial species, but unfortunately only a larva is known.

\section{Acknowledgements}

This study was carried out at the Caribbean Marine Biological Institute (CARMABI), Curaçao, and the Sentro Ekologiko, Bonaire. We thank Dr. W.L. Bakhuis and his staff of the former institute, and Drs. E. Newton of the latter, for hospitality during our stay.

Mr. J.J. Vermeulen, University of Amsterdam, rendered enthusiastic support during the fieldwork, especially in handling the biophreatical pump and other heavy equipment under tropical conditions and in places hard to reach by motorized transport.

The fieldwork was supported by a grant of the Committee for the Marine Biological Stations of the Royal Academy of Sciences, Amsterdam.

Dipl.-Biol. H.-G. Müller, University of Giessen (F.R.G.) is thanked for a preview of his unpublished data on Caribbean and Pacific Pycnogonida, of which we have made a very cautious and modest use in the above discussion on Rhynchothorax.

\section{References}

Arnaud, F., 1972. Un nouveau Pycnogonide de Méditerranée nord-occidentale: Rhynchothorax mediterraneus $n$. sp. et redécouverte de Rhynchothorax mediterraneus Costa, 1861, Téthys, 3(2) ('1971'): 405-409. 
Bou, $\mathrm{Cl} ., 1975$. Les méthodes de récolte dans les eaux souterraines interstitielles. Annls. Spéléol., 29(4): 611-619.

Child, C.A., 1974. Hedgpethius tridentatus, a new genus and new species, and other Pycnogonida from Key West, Florida, U.S.A. Proc. biol. Soc. Wash., 87(43): 493-500.

Child, C.A., 1979. Shallow-water Pycnogonida of the Isthmus of Panama and the coasts of Middle America. Smithson. Contr. Zool., 293: i-v, 1-86.

Child, C.A., 1982. Pycnogonida from Carrie Bow Cay, Belize. Smiths. Contr. mar. Sci., 12: 355-380.

Clark, W.C., 1976. The genus Rhynchothorax Costa (Pycnogonida) in New Zealand waters. J. roy. Soc. N. Z., 6(3): 287-296.
Hedgpeth, J.W., 1951. Pycnogonids from Dillon Beach and vicinity, California, with description of two new species. Wasmann J. Biol., 9(1): 105-117.

Krapp, F., 1973. A fourth Mediterranean Rhynchothorax and remarks on the genus (Pycnogonida). Bull. zoöl. Mus. Univ. Amsterdam, 3(17): 119-124.

Stock, J.H., 1986. Pycnogonida (= Pantopoda). In: L. Botosaneanu (ed.), Stygofauna Mundi: 698-700 (Brill/Backhuys, Leiden).

Received: 21 March 1989. 